\title{
Simulation of suspended sediment transport initialized with satellite derived suspended sediment concentrations
}

\author{
RATHEESH RAMAKRISHNAN* and A S RAJAWAT \\ Geosciences Division, Marine, Geo and Planetary Sciences Group, Earth, Ocean, Atmosphere, Planetary \\ Sciences and Applications Area, Space Applications Centre - ISRO, Ahmedabad 380 015, India. \\ *Corresponding author. e-mail: unnirathesh@gmail.com
}

\begin{abstract}
Suspended sediment transport in the Gulf of Kachchh is simulated utilizing the suspended sediment concentration (SSC) derived from Oceansat OCM imagery, as the initial condition in MIKE-21 Mud Transport model. Optimization of the model mud parameters, like settling velocity and critical shear stress for erosion are realized with respect to the sediment size distribution and the bottom bed materials observed in the Gulf. Simulated SSCs are compared with alternate OCM derived SSC. The results are observed to be impetus where the model is able to generate the spatial dynamics of the sediment concentrations. Sediment dynamics like deposition, erosion and dispersion are explained with the simulated tidal currents and OCM derived sediment concentrations. Tidal range is observed as the important physical factor controlling the deposition and resuspension of sediments within the Gulf. From the simulation studies; maximum residual current velocities, tidal fronts and high turbulent zones are found to characterise the islands and shoals within the Gulf, which results in high sediment concentrations in those regions. Remarkable variability in the bathymetry of the Gulf, different bed materials and varying tidal conditions induces several circulation patterns and turbulence creating the unique suspended sediment concentration pattern in the Gulf.
\end{abstract}

\section{Introduction}

Monitoring and understanding the sediment dynamics and suspended sediment transport is an important issue for coastal engineering related activities. A study on the transport mechanism of suspended sediments in marine environment is essential not only for the safeguard of marine installations or navigational channels but also to make out an assessment on the pollutants and other biological activities in the region.

Conventional methods of monitoring suspended sediment concentration (SSC) through in-situ measurements are difficult, expensive and are point observations whereas remote sensing-based data provide large area coverage and are repetitive observations which are more reliable and quick to obtain. Satellite-derived SSC data provided by IRS-P4 Ocean Color Monitor (OCM) have been found to be useful for Indian region, due to its high spatial and spectral resolution, good temporal resolution and a local pass at 12:00 hrs IST. In spite of 2-day revisit period, OCM observations are inadequate to understand the sediment dispersion by the alternating tidal currents in regions like Gulf of Kachchh, while numerical

Keywords. Suspended sediment concentrations; OCM; sediment transport model; tide. 
simulation of sediment transport has the advantage of continuous observation of sediment dynamics and understanding the sediment behaviour in the alternating tidal currents.

Numerical simulation of sediment transport is achieved by hydrodynamic-transport coupled models. The simulation of sediment transport models by Liang et al. (2007), Cancino and Neves (1999) and Ulses et al. (2008) were based on field observations whereas Zhang and Hua (2007) and Douillet et al. (2001) have resorted to the theoretical values and lab measurements to validate the transport model. Quillon and Caussade (1991) have described the effective use of satellite remote sensing data in modelling sediment transport. Quillon et al. (2004) have coupled remote sensing data with in situ measurements to simulate suspended sediment transport in New Caledonia Lagoon.

Initial distribution of sediment concentrations are of critical importance for sediment transport modelling (Lee et al. 2007). Often, the initial concentrations are assumed to be constant for the entire model domain or uses field observations which are rather scattered point observations. The present study utilises the sediment concentration values derived from OCM as initial sediment concentrations for a numerical model to simulate its transport under the hydrodynamics prevailing in Gulf of Kachchh.

\subsection{Study area and environmental setting}

Gulf of Kachchh $\left(68^{\circ} 20^{\prime}-70^{\circ} 40^{\prime} \mathrm{E} ; 22^{\circ} 15^{\prime}-23^{\circ} 40^{\prime} \mathrm{N}\right)$ is an east-west oriented; macro-tidal region in the west coast of India (figure 1). The Gulf is a high energetic system where the highest high tide reaches about $6.6 \mathrm{~m}$ at Kandla and $7.2 \mathrm{~m}$ at Navalakhi. Studies have reported that the natural period of the Gulf is close to 10 hours (Unnikrishnan and Luick 2003), causing amplification of the constituents,whereas Shetye (1999) has observed an additional amplification of constituents due to the funnel-shaped geometry of the Gulf.

In situ data were used to understand the sediment characteristic of the Gulf in their studies by Hashimi et al. (1978), Nair et al. (1982) and Ramaswamy et al. (2007). The complex system of the Gulf is composed with fragile marine eco system where, amid the tidal channels, are small shoals and coral islands, controlling the tidal current patterns and sediment dynamics within the Gulf. From the hydrodynamic simulation of tidal currents, the contrast in mixing and transport pattern between the outer and inner Gulf was reported by Kankara et al. (2007) which could be probably due to the existence of a dynamic barrier along Sikka-Mundra section, which divides the Gulf into two distinct dynamic systems as reported by Vethamony et al. (2005). Babu et al.

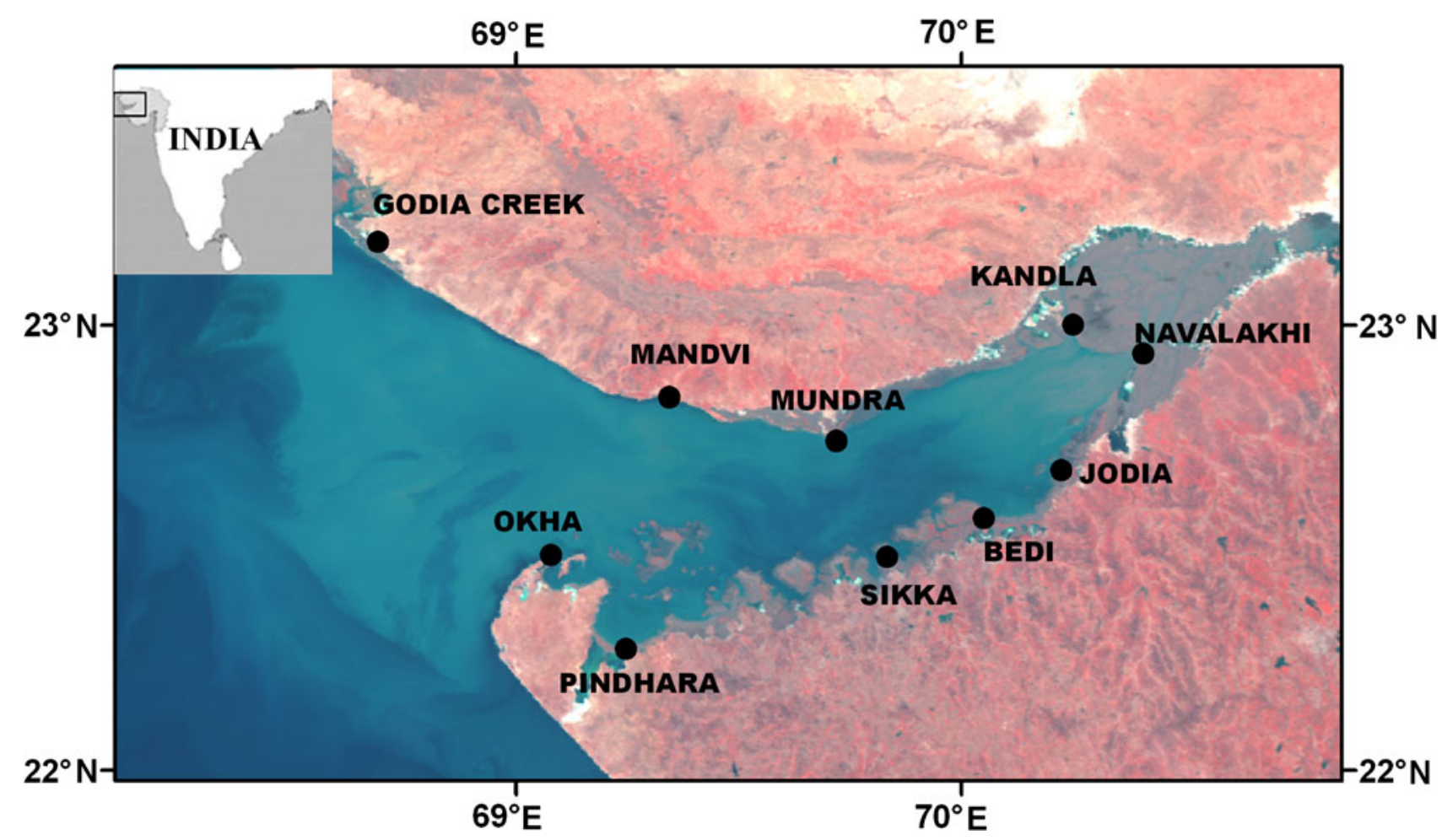

Figure 1. Location map of Gulf of Kachchh. 
(2005) studied the residual eddy currents within the Gulf using numerical modelling of tidal circulations. Hydrodynamic simulation studies alone were found to be ineffective in understanding various sediment dynamics and the use of satellite data in conjunction with the numerical results were opted by Kunte et al. (2005) and Chauhan et al. $(2006,2007)$ to comprehend the sediment distribution and source to sink pathways of sediment fluxes.

Babu et al. (2003) have studied the sediment transport along Mangalore coast in the Arabian Sea using model results.

In the present study, sediment transport in the Gulf of Kachchh is simulated from the concentration information derived from OCM observations. An attempt is made to understand the relation of tidal currents to the sediment dynamics of the Gulf.

\section{Data and methodology}

\subsection{Satellite image}

Remote sensing of oceanic and coastal waters depends upon the interaction of light with optically active water constituent such as phytoplankton, total suspended matter and dissolved organic matter, also known as yellow substance. A large number of sensors are developed by Indian and other space agencies, which are dedicated to determine the ocean parameters optically. OCM onboard Oceansat-1 collects data in eight spectral channels $(402-422,433-453,480-500,500-520,545-$ $565,660-680,745-785$ and $845-885 \mathrm{~nm})$ with temporal resolution of 2 days at a local time 12:00 hrs. Each OCM scene covers $1420 \times 1420 \mathrm{~km}$ ground area.

From the first six channels corresponding to the visible spectrum, water leaving radiance $\left(L_{w}\right)$ is extracted after correcting for the atmospheric constituents. The sensor observed radiance $\left(L_{t}\right)$ can be partitioned into components corresponding to distinct physical processes like Rayleigh scattering by the atmospheric gaseous constituents $\left(L_{r}\right)$, scattering by the aerosol particles $\left(L_{a}\right)$ and the water leaving radiance $\left(L_{w}\right)$ (Doerffer 1992). $L_{r}$ is computed from its spectral dependency, which leaves $L_{a}$ as the unknown to be determined to obtain $L_{w}$ from $L_{t} . L_{w}$ at band 7 and band 8 in the near infrared (NIR) region is assumed to be negligible enabling estimates of NIR $L_{a} . L_{a}$ at visible bands is obtained by extrapolating the NIR $L_{a}$ using aerosol model. The detailed descriptions are given in Gordon (1997).

Even though a large number of sediment algorithms have been proposed to quantify total suspended matter (Miller and McKee 2004; Pradhan et al. 2005; Erico et al. 2007), universal sediment algorithms are unavailable (Acker et al. 2005). In the current study, from the water leaving radiances, SSC values were derived from algorithm initially proposed by Tassan (1994) and later undergone site specific modification (Chauhan et al. 2006):

$\log (S)=1.83+1.261 \log \left(X_{s}\right) \quad 0.0 \leq S \geq 40.0$

where $S$ is the SSC in $\mathrm{mg} / \mathrm{l}$ and $X_{s}$ is defined as:

$$
\begin{aligned}
X_{S}=\{ & \left.R_{r s}(555)+R_{r s}(670)\right\} \\
& \times\left[R_{r s}(490) / R_{r s}(555)\right]^{-0.5}
\end{aligned}
$$

where $R_{r s}(\lambda)$ is the remote-sensing reflectance in respective wavelengths.

Chauhan et al. (2007) have used the same SSC retrieval algorithm in the Gulf of Kachchh region to obtain the SSC distribution patterns within the Gulf. Their study have compared OCM derived SSC with in situ, pass synchronous and random measurements and observed that the OCM SSC are underestimated by $\pm 25 \%$. Pradhan et al. (2004) have utilized OCM derived sediment inputs to study the impact of tidal propagation on the sediment dynamics of the Gulf. In their study by Chauhan et al. (2006), the contribution of sediments from the River Indus into the Gulf of Kachchh was made observed using OCM derived SSC. SSC in the Gulf of Kachchh was derived from SeaWiFS data using Tassan algorithm by Kunte et al. (2005) to study the sediment distribution of the Gulf. It is observed that the SSC values obtained from OCM shows rather a relative value than the absolute value of SSC. The acceptability of the satellite derived SSC lays in its ability to preserve the general pattern of sediment distribution (Chauhan et al. 2007; Peckham 2008).

Geometric correction is applied separately on individual datasets to remove image distortion and bring them to a standard geographic projection. Image to image rectification is done among the sequential satellite data to obtain an error limit restricted to one pixel $(360 \mathrm{~m})$. Cloud free OCM scenes for January 2005 are selected to understand the spatial distribution of the suspended sediment in the Gulf.

\subsection{Simulation of tidal currents}

Simulation of tidal currents in Gulf of Kachchh is done using Hydrodynamic (HD) module of MIKE21. MIKE-21, developed by the Danish Hydraulic Institute, Denmark, is a software package 
containing a comprehensive modelling system for 2D free-surface flows. The flow field is calculated from the solution of depth integrated equations of conservations of volume and momentum in $\mathrm{x}$ and y directions (Abbott 1979) given as:

$\mathrm{x}$-momentum:

$$
\begin{aligned}
\frac{\partial p}{\partial t}+ & \frac{\partial}{\partial x}\left[\frac{p^{2}}{h}\right]+\frac{\partial}{\partial y}\left[\frac{p q}{h}\right]+g h \frac{\partial \eta}{\partial x} \\
+ & {\left[g \frac{\sqrt{\frac{p^{2}}{h^{2}}+\frac{q^{2}}{h^{2}}} \frac{p}{h}}{C^{2}}\right]-f V V_{x}-\frac{h}{\rho w} \frac{\partial P_{a}}{\partial x} } \\
& -\Omega q-E=S_{i x}
\end{aligned}
$$

y-momentum:

$$
\begin{aligned}
\frac{\partial q}{\partial t}+ & \frac{\partial}{\partial x}\left[\frac{q^{2}}{h}\right]+\frac{\partial}{\partial y}\left[\frac{p q}{h}\right]+g h \frac{\partial \eta}{\partial y} \\
& +\left[g \frac{\sqrt{\frac{p^{2}}{h^{2}}+\frac{q^{2}}{h^{2}} \frac{q}{h}}}{C^{2}}\right]-f V V_{y}-\frac{h}{\rho w} \frac{\partial P_{a}}{\partial y} \\
& -\Omega q-E=S_{i y}
\end{aligned}
$$

the equation of continuity:

$$
\frac{\partial \eta}{\partial t}+\frac{\partial p}{\partial x}+\frac{\partial q}{\partial y}=S-e
$$

$P$ and $q=$ the flux in the $\mathrm{x}$ and y directions, respectively, $h=$ water depth, $t=$ time, $P_{a}=$ atmospheric pressure, $\rho_{w}=$ density of water, $g=$ acceleration due to gravity, $h=$ surface elevation $(\mathrm{m}), e=$ evaporation rate ( $\mathrm{mm} /$ day), $C=$ Chezy's coefficient, $f=$ wind friction factor, $V=$ Coriolis force, $S_{i x}$ and $S_{i y}=$ source impulse in x and y directions, $E=$ eddy viscosity coefficient, and $\Omega=$ Coriolis parameter.

The domain is selected to include the entire Gulf of Kachchh. Available NHO (National Hydrographic Office) hydrographic chart is used to create the bathymetry (figure 2). The resolution of bathymetry is chosen as that of the spatial resolution of OCM, which is $360 \mathrm{~m}$. For the purpose of classification of the Gulf according to the bathymetry, the region deeper than $27 \mathrm{~m}$ is termed as tidal scour channel of the Gulf (figure 2).

As river input into the Gulf can be neglected (Ramaswamy et al. 2007), eastern part of the Gulf is closed so that water enters the Gulf only through the west (open ocean). The model is forced using the tidal elevation at the open boundary, with Godia creek on the north and Okha on the south. Tidal elevations for the above-mentioned stations are obtained from MIKE-CMAP tidal extraction tool at an interval of $30 \mathrm{~min}$. A constant wind of $5 \mathrm{~m} \mathrm{~s}^{-1}$ and wind friction factor of 0.0026 , resistance of $38 \mathrm{~m}^{1 / 3} \mathrm{~s}^{-1}$ and horizontal eddy viscosity of $0.5 \mathrm{~m}^{2} \mathrm{~s}^{-1}$ are given to the model as suggested by Babu et al. (2005). The simulation is carried out for January 2005.

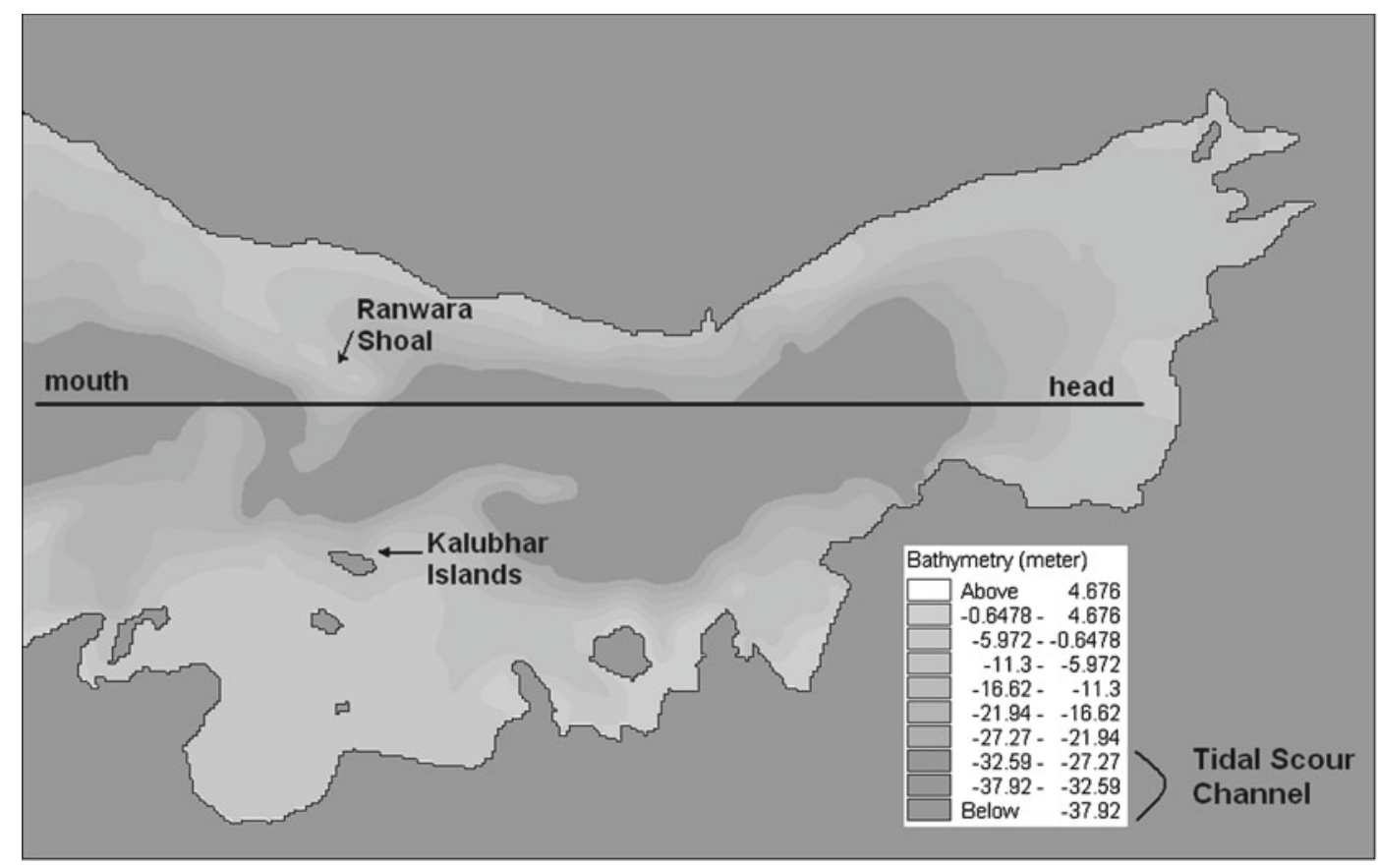

Figure 2. Model domain and the bathymetry of the region. (For comparison, the SSC from OCM and model is extracted along the line drawn from mouth to head.) 


\subsection{Integration of satellite-derived SSC into the sediment transport model}

Coupling of remote sensing and numerical models were reported by Quillon et al. (1998) where the applicability of remote sensing to provide initial data or boundary forcing to a numerical model was detailed. In the present study, the synoptic distribution of SSC derived from OCM for 1 January 2005 (figure 3) is taken as the initial condition of sediment concentration in a numerical model to simulate the suspended sediment transport. Geometrically corrected OCM scene is brought to geographic projection as that of bathymetry file prepared for the numerical simulation. The error limit was restricted to one pixel which made sure that the SSC maps derived from OCM exactly fits over the bathymetry file. These sediments (OCM derived) are then advected with the tidal currents (simulated from MIKE-21 HD) imparting dispersion and settling of the sediments. The sediment transport models are configured to run in conjunction with the hydrodynamic model. MIKE-21 Mud Transport (MT) model is used to simulate suspended sediment transport within the Gulf of Kachchh. The MT module describes erosion, transport and deposition of silt, mud and clay particles under the action of currents and waves.

The governing equation for the suspended sediment transport model is:

$\frac{\partial C}{\partial t}+u \frac{\partial C}{\partial x}+v \frac{\partial C}{\partial y}=K_{x} \frac{\partial^{2} C}{\partial x^{2}}+K_{y} \frac{\partial^{2} C}{\partial y^{2}}+\frac{\varphi_{r}-\varphi_{s}}{h}$ where $C=$ depth-averaged concentration of suspended sediment, $u, v=x$ and $y$ components of depth-averaged of current velocity derived from the hydrodynamics model, $K_{x}, K_{y}=$ depth mean dispersion coefficients in $\mathrm{x}$ and $\mathrm{y}$ directions, $\varphi_{r}=$ re-suspension flux, $\varphi_{s}=$ sedimentation flux, and $h=$ total depth.

Settling velocity and critical shear stress of erosion are two important mud parameters of the model. For grains to get deposited from the suspended load, the settling velocity $w_{s}$ of the grains in suspension should be greater than the upward turbulent component of velocity. The settling velocity of grains is calculated according to the suspended sediment size distribution maps within the Gulf compiled from the field observations of Ramaswamy et al. (2007).

Settling velocity is calculated from the equation given by Soulsby (1997)

$$
w_{s}=\frac{\nu}{d_{50}}\left[\left(10.36^{2}+1.049 D_{*}^{3}\right)^{1 / 2}-10.36\right]
$$

where $d_{50}$ is the grain size diameter, $\nu$ is the kinematic viscosity of water $=1.36 \times 10^{-6} \mathrm{~m}^{2} / \mathrm{s}$, and $D_{*}$ is the dimensional size parameter.

$$
D_{*}=\left[\frac{g(s-1)}{\nu^{2}}\right]^{1 / 3} d_{50}
$$

where $g$ is the gravity, and $s$ is the ratio of densities of sediment and water.

For very slow flow over a sand bed, the sand remains immobile, but as the flow velocity is increased slowly, a velocity is reached at which a

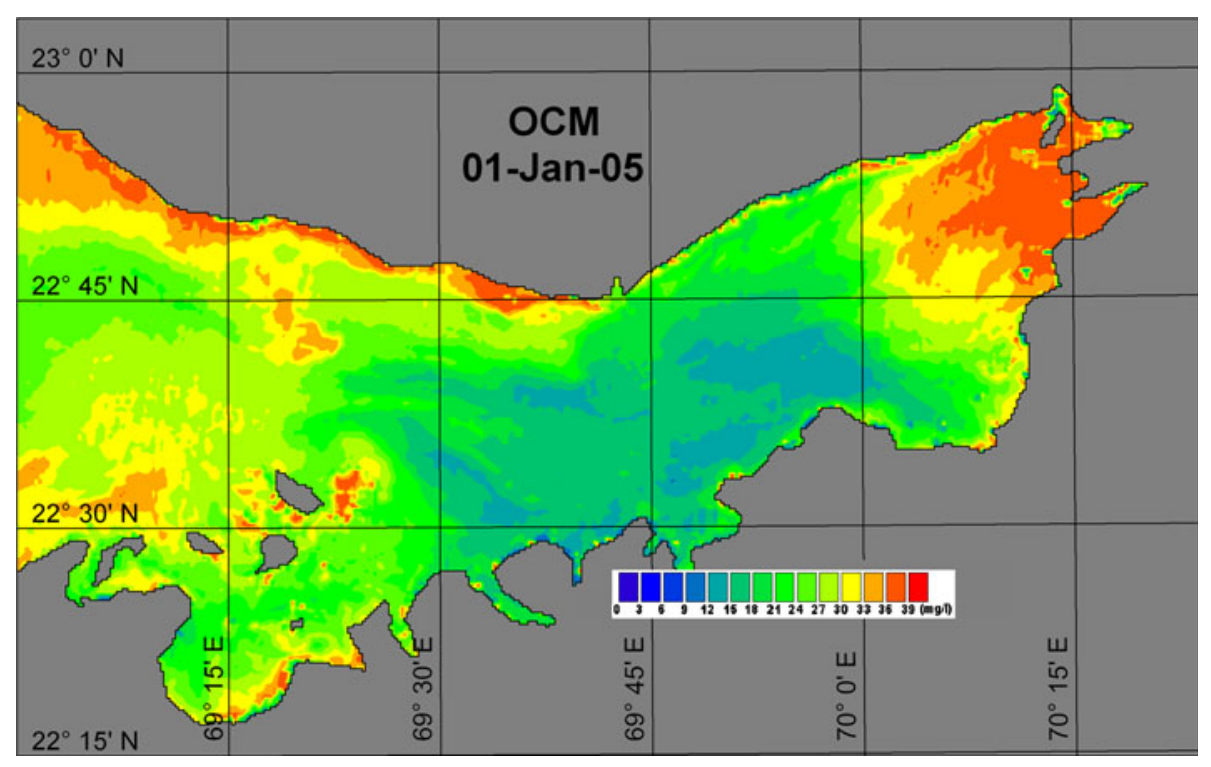

Figure 3. SSC for 1st January $2005 \mathrm{in} \mathrm{mg/l} \mathrm{(initial} \mathrm{concentration} \mathrm{for} \mathrm{simulation} \mathrm{of} \mathrm{sediment} \mathrm{transport} \mathrm{model).}$ 


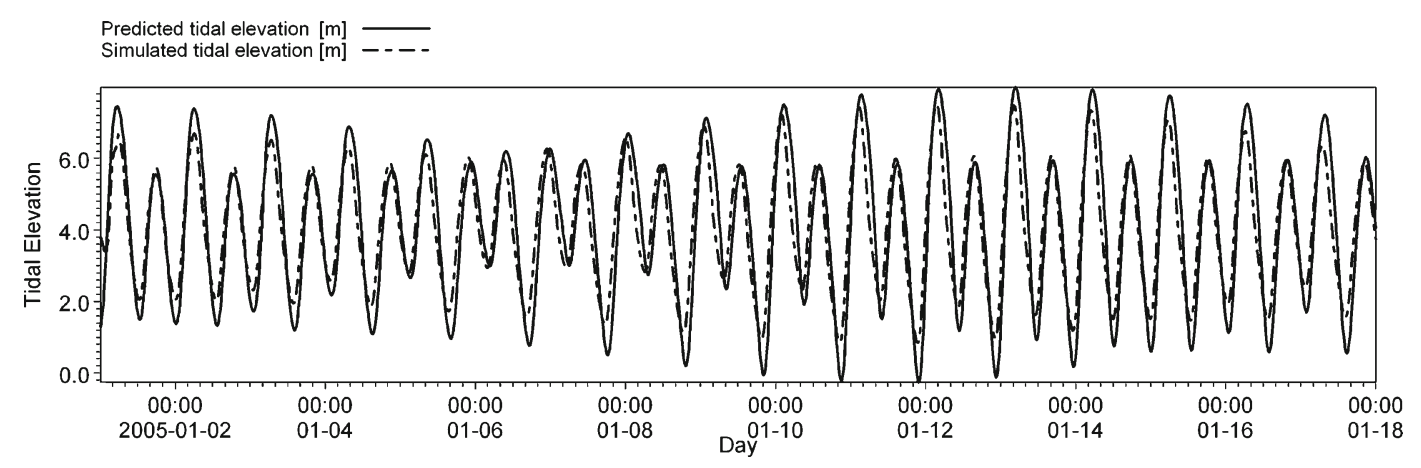

Figure 4. Comparison of simulated and predicted tidal elevation for Navalakhi.

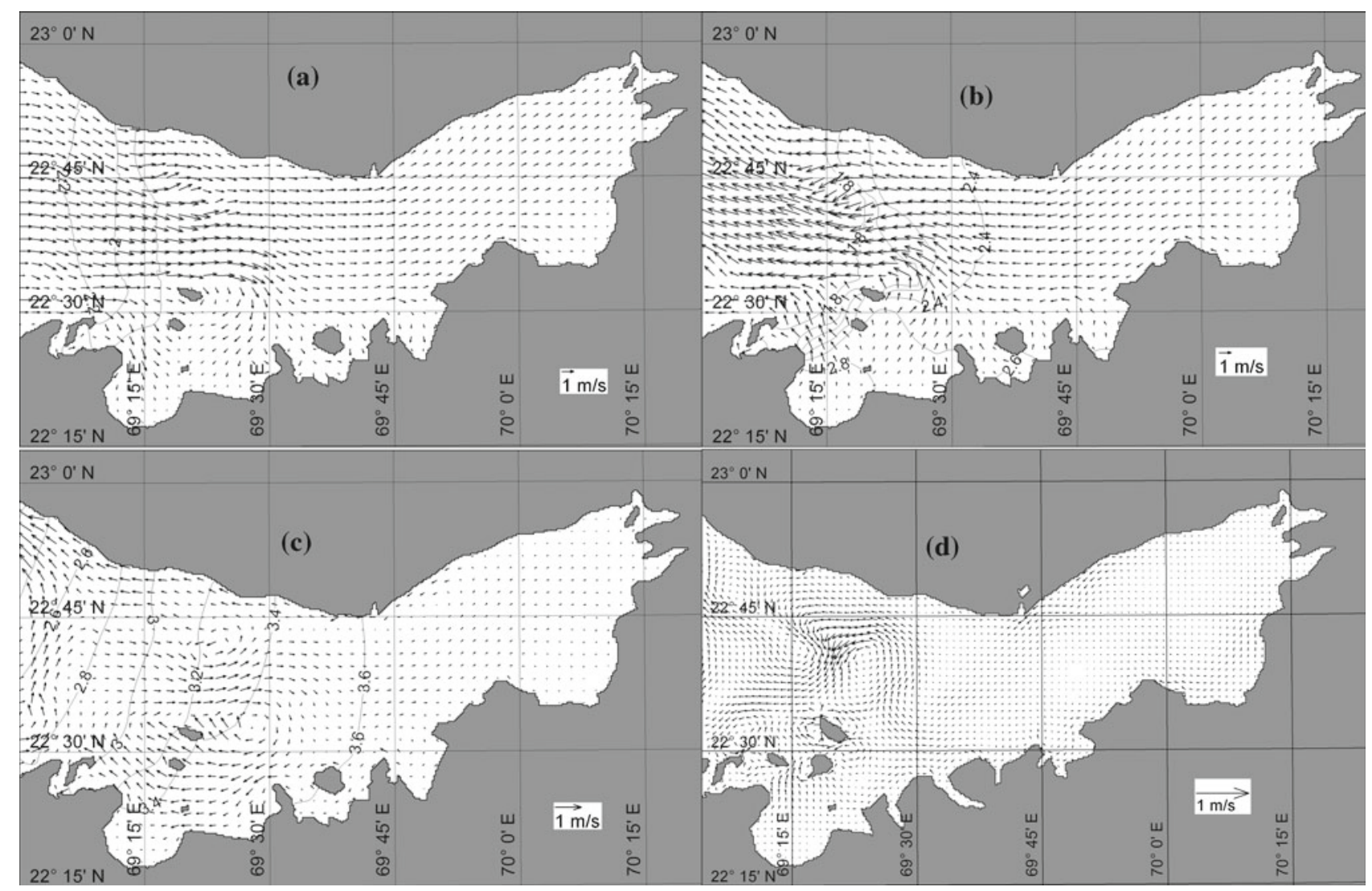

Figure 5. (a) Flood current pattern in Gulf of Kachchh, (b) ebb current pattern in Gulf of Kachchh, (c) current pattern in Gulf of Kachchh during reversal of tide and (d) residual current in Gulf of Kachchh computed for four tidal cycles.

few grains begin to move. This is called threshold of motion. The bed shear stress associated with the threshold of motion is called critical bed shear stress $\tau_{c r}$. The spatial variation of critical shear stress within the Gulf is evaluated according to the bed form distribution of Gulf of Kachchh compiled by Kunte et al. (2003).

$$
\tau_{c r}=\theta_{c r} g d_{50}\left(\rho_{s}-\rho\right)
$$

where $\rho$ is the water density $=1027 \mathrm{~kg} / \mathrm{m}^{3}, \rho_{s}$ is the sediment density, and $\theta_{c r}$ is the shield parameter.

$$
\theta_{c r}=\frac{0.30}{1+1.2 D_{*}}+0.055\left[1-\exp \left(-0.020 D_{*}\right)\right]
$$

Winter (2007) has described the significance of statistical parameters for the evaluation of 
sediment transport model. SSC derived from subsequent OCM images for 3rd, 5th and 7th January 2005 are used for the statistical evaluation of the model results.

\section{Results and discussion}

\subsection{Tidal simulation}

Simulation is carried out to obtain the tidal current within the Gulf of Kachchh for January 2005.
In the absence of synchronous current measurements, the simulation is validated with predicted tidal elevation for Navalakhi in the eastern side of the domain (closed boundary). The comparison of the model and predicted tidal elevation (figure 4) confirms that the model reproduces the phase and amplitude with the predicted tide. Figure 5(a) depicts the surface current distribution during high tide time. During the high tide, the current enters the Gulf with a maximum speed of $2.8 \mathrm{~m} / \mathrm{s}$. The distribution of ebb current is shown in figure $5(\mathrm{~b})$, with a maximum speed of $2.47 \mathrm{~m} / \mathrm{s}$.
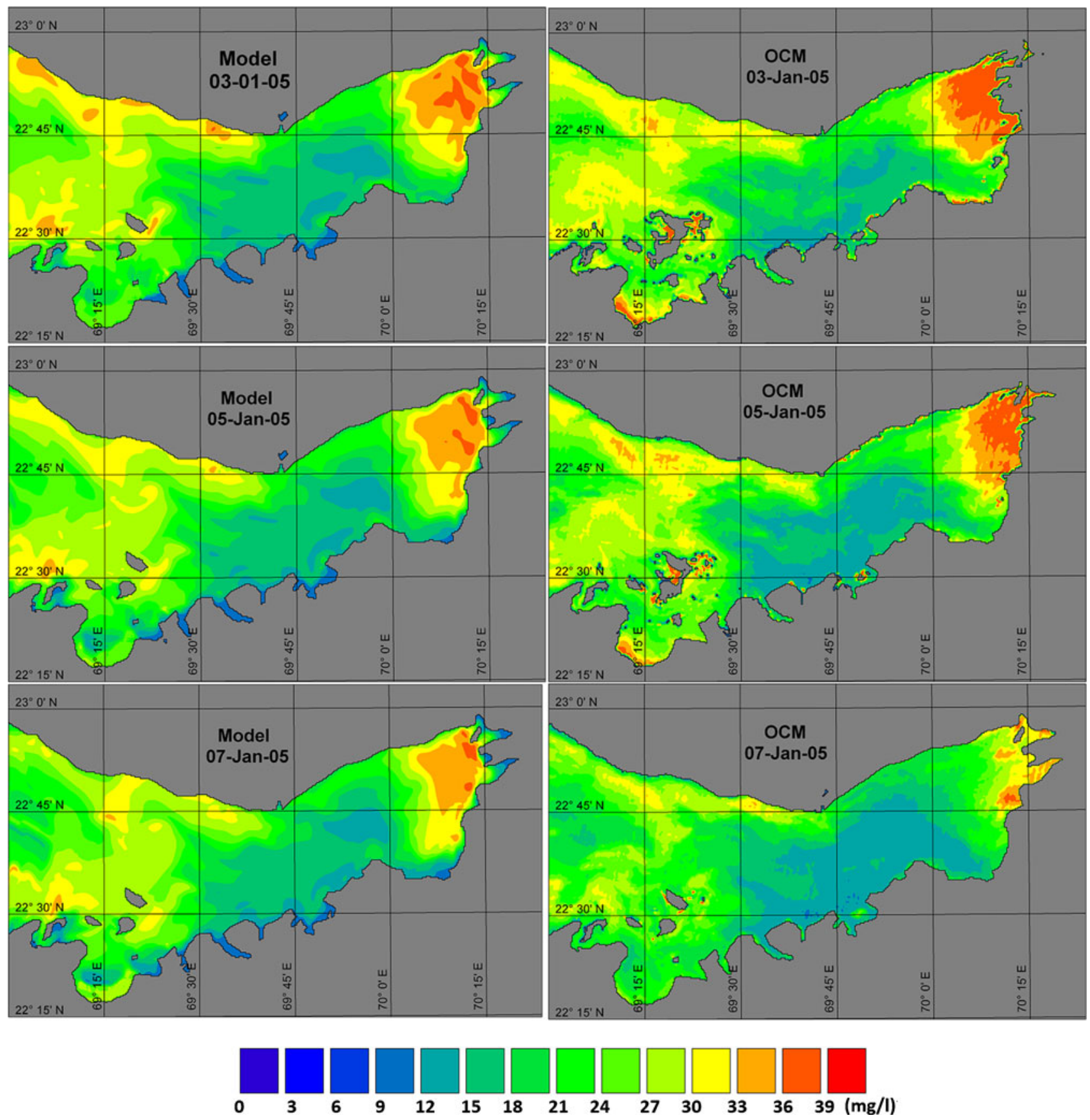

Figure 6. Comparison of simulated SSC with OCM derived SSC (mg/l). 
Figure 5(c) shows the current pattern during the reversal of current from flood to ebb. Co-tidal line from figure 5(c) indicates that tide in the Gulf is ebb, but the currents in the tidal scour channel (shown in figure 2) are observed to flow eastwards (characteristic of a flood tide), that is, currents in the tidal scour channel lag behind the tidal elevation. In the tidal scour channel, currents have large
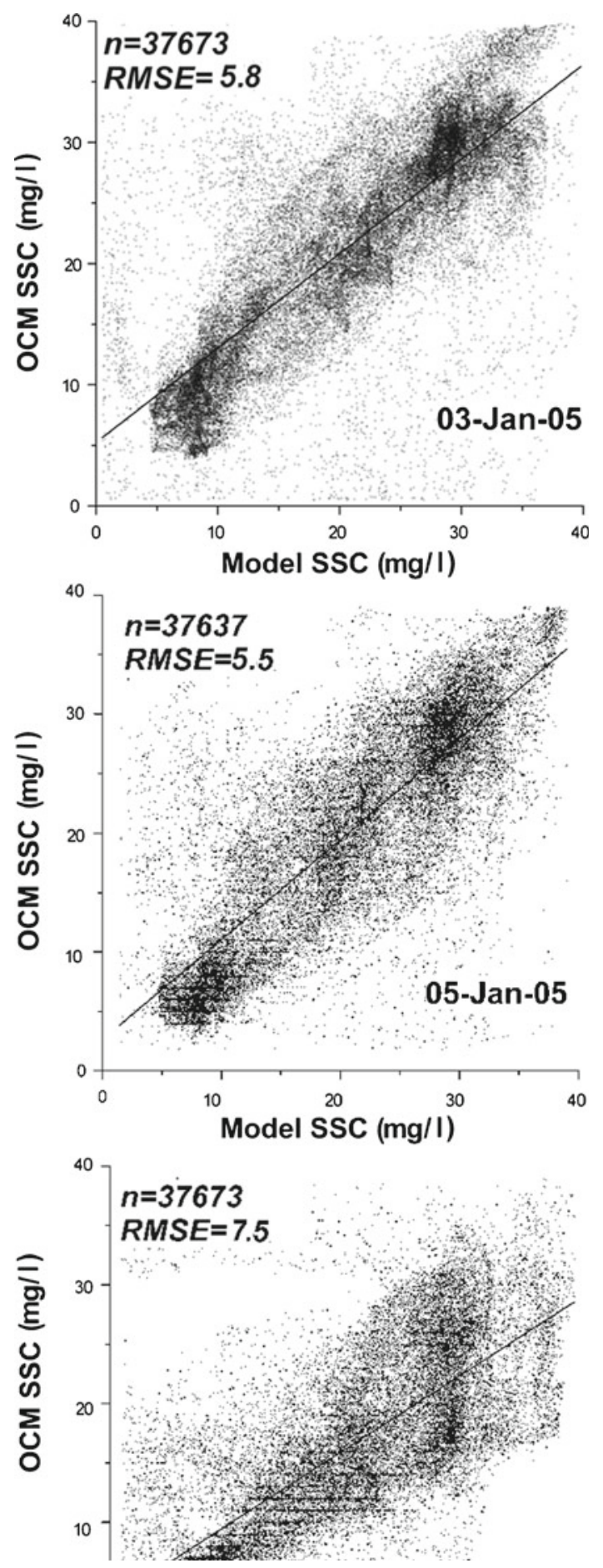

Figure 7. Scatter plot showing the comparison of simulated SSC with OCM SSC. velocity and momentum and thus a lower response to the change in tide. Towards the coast, the current velocities are small with smaller momentum and follow the tidal elevation without any significant time lag. Tidal fronts are formed at the conjunction of these opposing currents which are characterized by high turbulence. Eddies are also observed during the reversal of the tide (figure $5 \mathrm{c}$ ).

The residual currents are calculated by taking average of the velocities for a period of four tidal cycles (figure 5d). Several clockwise and anticlockwise eddies are observed within the Gulf confined to the islands and shoals where a sudden change in the depth occurs.

\subsection{Simulation of suspended sediment transport}

Simulation of suspended sediment transport is carried out by optimizing the model control parameters like settling velocity and critical shear stress for erosions. The settling velocity given is $0.0002 \mathrm{~m} / \mathrm{s}$ and the critical shear stress for erosion is obtained in the range of $0.05-2.00 \mathrm{~N} / \mathrm{m}^{2}$, where the low value coincides with region of soft sediment bed and larger value corresponds to
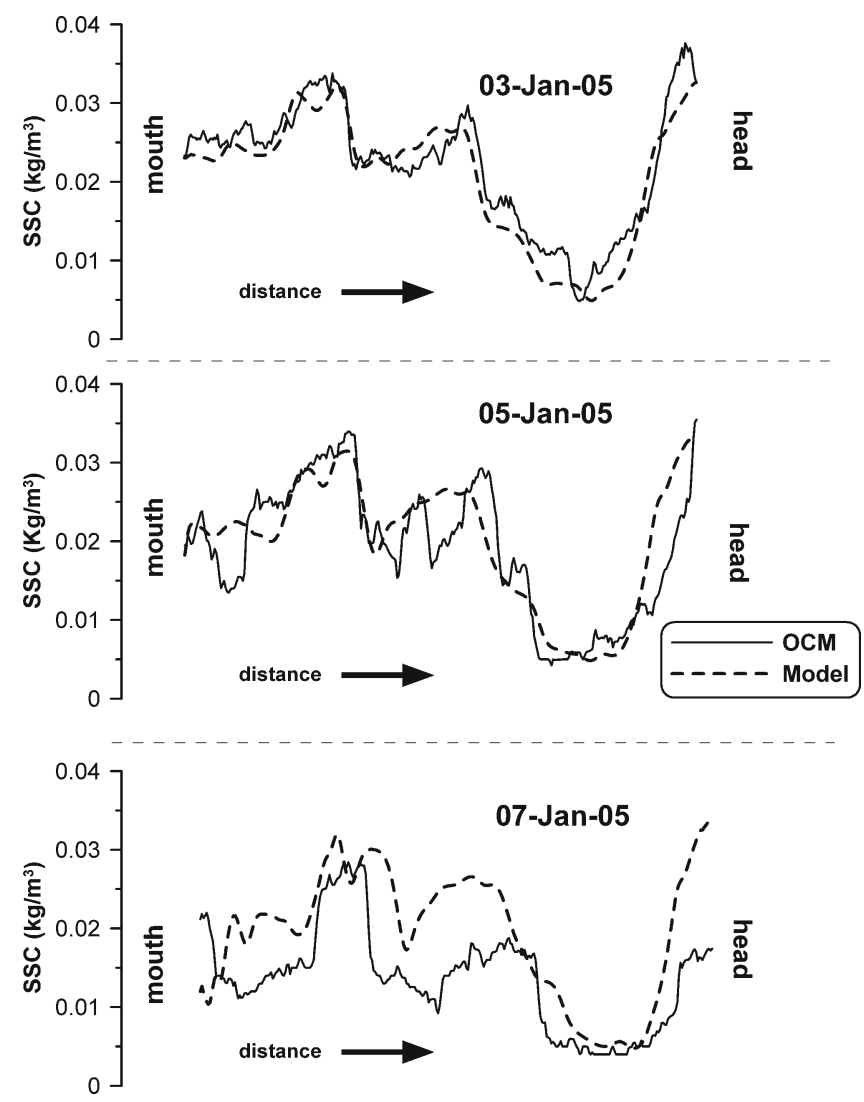

Figure 8. Comparison of simulated SSC and OCM SSC extracted along the line. 


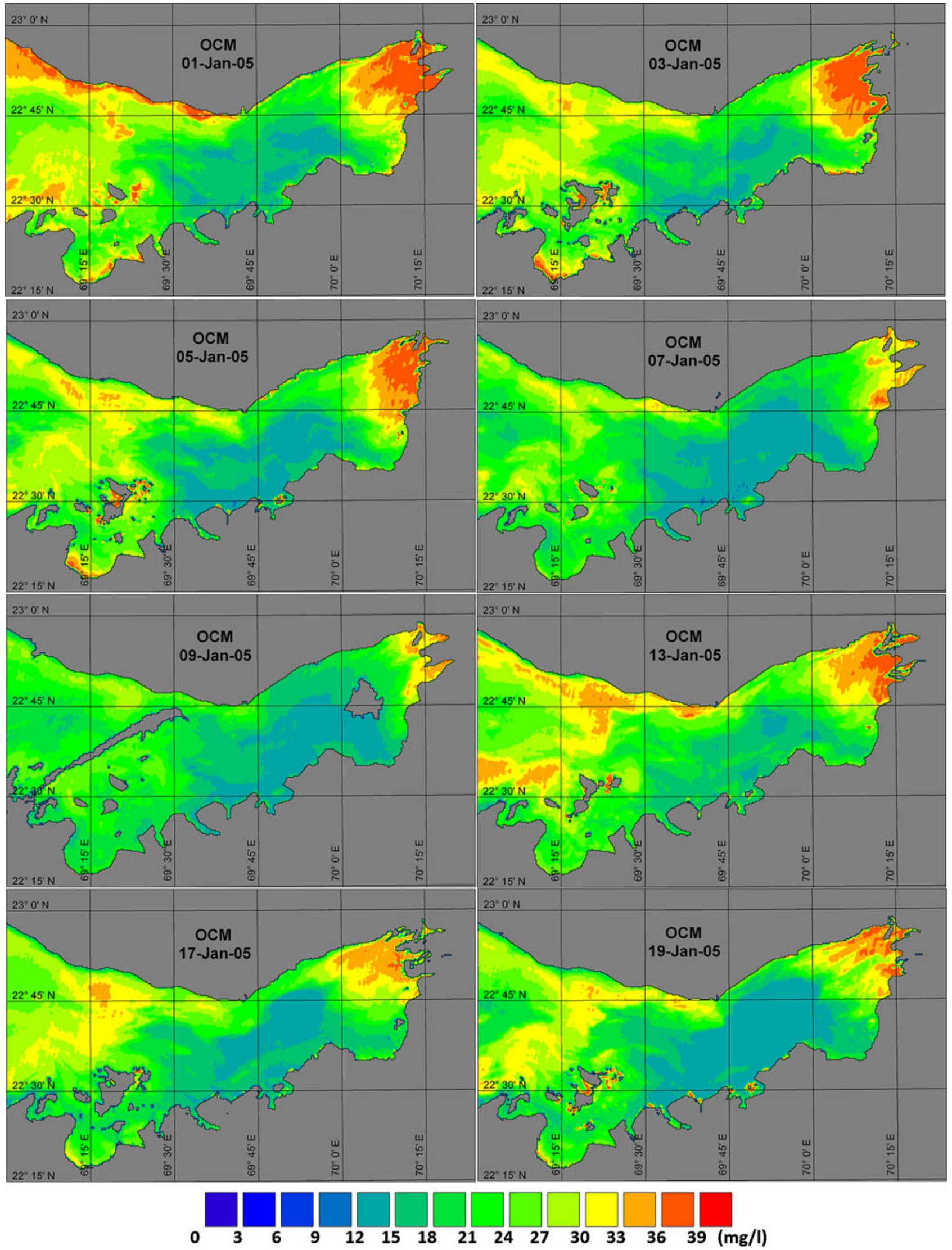

Figure 9. OCM-derived SSC (mg/l) for January 2005. 
area with hard sediment bed forms. Simulation of sediment transport is carried out from 1st January 2005 12:00 hrs by taking OCM-derived SSC as the initial concentration.

SSC obtained from the model at 12:00 hrs for 3rd, 5th and 7th January 2005 is visually compared with the corresponding OCM derived SSC (figure 6). A statistical comparison is done from the scatter plot shown in figure 7 . The RMS error is found to be 5.8 and $5.5 \mathrm{mg} / \mathrm{l}$ for $3 \mathrm{rd}$ and 5th January 2005 and for 7th January 2005 the RMS error was $7.5 \mathrm{mg} / \mathrm{l}$.

From OCM and corresponding simulated results, SSC is extracted along the line shown in figure 2. From the comparison of the SSC extracted along the line, it is observed that the model is able to simulate the general trend in the spatial variation of SSC (figure 8). The correlation coefficient for 3rd January 2005 is 0.95 which got declined to 0.85 and 0.74 for 5 th and 7 th January 2005.

The simulation result shows an increase in SSC near the islands and shoals within the Gulf when the current velocity is higher. The swift action of the tidal current scours the bottom sediment in these regions and brings it to suspension. The model results and OCM show a gradual decrease in SSC from January 1st to 7th.

\subsection{OCM Observations and the sediment dynamics}

SSC is derived from cloud free OCM scenes for the month of January 2005 (figure 9). The mean $\mathrm{SSC}$ is calculated for each scene (figure 10a). A gradual decrease in the mean $\mathrm{SSC}$ is seen from 1st to 9th January 2005. On 13th January 2005 SSC values are high, which decreased gradually for the subsequent images. The temporal variations in SSC within the Gulf are associated with the variations in tide range. Figure 10(b) shows the tide range in Gulf of Kachchh during the observations. From 1st to 8th January 2005, the tide in the Gulf is neap where the tidal range is between 2.6 and $2.8 \mathrm{~m}$. From simulation results the current velocity was found to be in the range of $0.7-0.9 \mathrm{~m} / \mathrm{s}$. Low current velocities during the neap tide caused deposition of suspended sediments within the Gulf. The spring tide that followed (from 10th to 16th January 2005) is having a tide range of $3.0-3.32 \mathrm{~m}$ and from the simulation, current velocity obtained is in the range $2.2-2.8 \mathrm{~m} / \mathrm{s}$. The high velocity currents triggered the re-suspension of the deposited sediments resulting in high values of SSC on 13th January 2005.

The relation between residual current and the turbidity was shown by Kunte et al. (2005) and
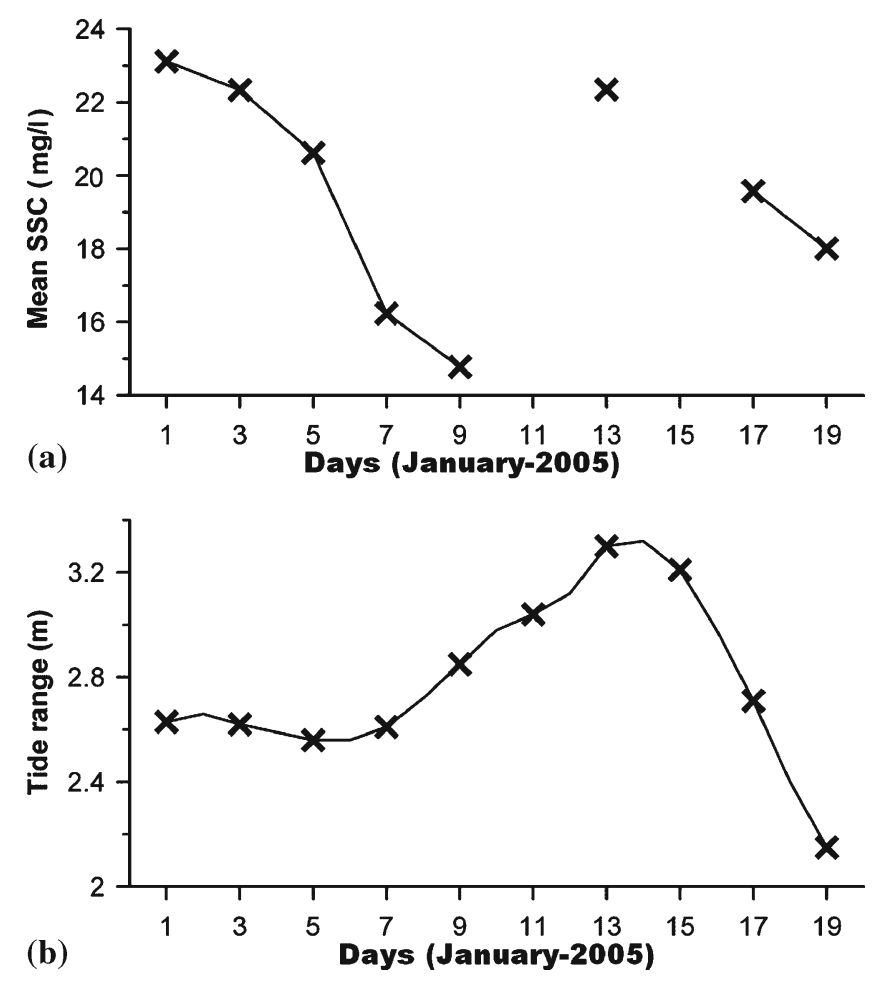

Figure 10. (a) Mean SSC during the observation (data gap shows non-availability of OCM for 11th and 15th January 2005) and (b) the tide range in Gulf of Kachchh during the observations.

similarly high residual velocities are observed (figure 5d) near the islands and shoals which corresponds to high value for SSC from OCM observations. High SSC values in these regions are also attributed to the tidal fronts. The opposing currents (figure $5 \mathrm{c}$ ) formed during the reversal of tide produces the tidal fronts which are characterized by high turbulence that keeps the sediments in suspension.

In the southern coast near to Pindhara, a strip of high SSC is observed from OCM for almost all scenes but the model is unable to produce this high SSC strip. The possible reason could be that the sediment influx from adjoining creek that opens into the Gulf causing high SSC values in the region. In figure 11, OCM-derived SSC of 3rd January 2005 is overlaid with the corresponding simulated tidal current. It can be seen from the figure that the dispersion pattern of the current and sediment along Pindhara coast is across shore (perpendicular to the coast) whereas the current and sediment dispersion in the northern coast is along shore (parallel to the coast).

Patches of high SSC are also seen at the head (eastern side) of the Gulf in both the OCM scenes and in the simulation results. The soft sediments in these shallow regions are subjected to deposition and erosion owing to the variations in the velocity of the tidal currents. In the mid Gulf, a 


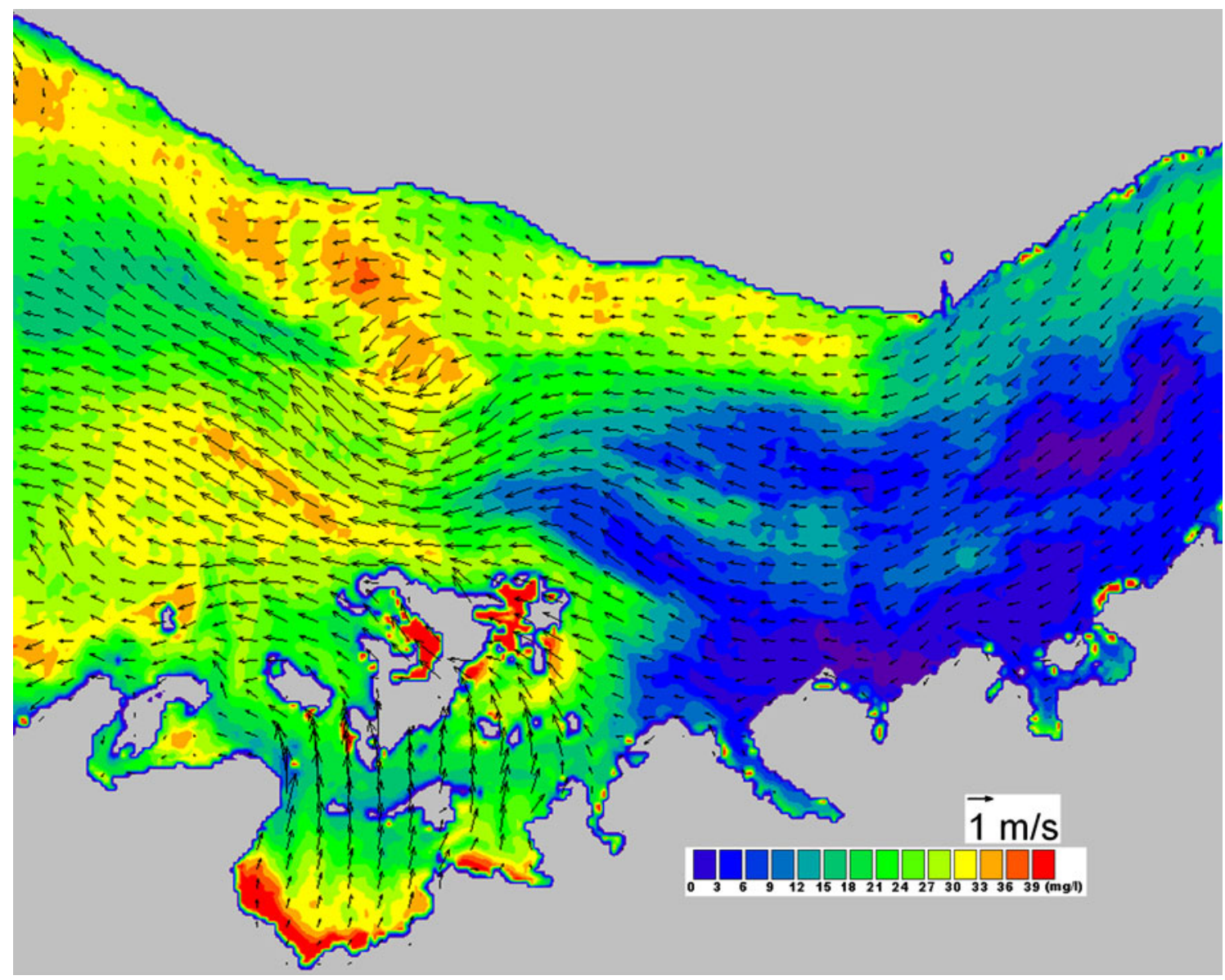

Figure 11. OCM-derived SSC for 3rd January 2005 overlaid with simulated current.

region of low concentrations of SSC is observed from both OCM and simulation results. A possible reason for low SSC region might be that a dynamic barrier exists across the Sikha-Mundra section Vethamony et al. (2005); Kankara et al. (2007). Existence of this barrier could make the portion of Gulf to the right of this barrier devoid of sediment inputs from the river Indus. The region corresponding to low SSC values in the mid Gulf is also the deeper portion of the tidal channel, which makes the re-suspended sediments from the bed difficult to be observed by the OCM.

\section{Conclusions}

The viability of utilizing satellite derived sediment concentrations for simulating sediment transport within the Gulf of Kachchh is shown in the present study. The statistics obtained from the comparison of model simulated SSC and OCM-derived SSC is conducive for the explanations of sediment dynamics in the Gulf using the model results. When compared with OCM, the model results showed a gradual increase in RMSE with time. Due to the lack of wind data, effect of varying winds are not included in the simulation. It is also expected that with the development of improved algorithms for Case-2 waters to retrieve suspended sediments, such simulations shall provide near-real quantification of suspended sediments. The simulation results can also be further improved by including the sediment influxes from the creeks and smaller rivers that open into the Gulf.

There is a significant deposition and resuspension processes within the estuary controlled by the varying tidal ranges. The complexity in bathymetry and the coastline plays vital role in influencing the tidal currents and sediment distribution patterns in the Gulf region. Region of high turbulent zone with eddy formations and maximum residual velocities are obtained near the shoals and islands which coincide with high sediment concentrations. Deep tidal scour channels in the mid Gulf are found to be devoid of high suspended sediment concentrations throughout the observations. The distinct variability in the bathymetry leads to spatial variation in tidal velocities which controls the disparity in the suspended sediment distributions in the Gulf. 


\section{Acknowledgements}

The authors express their sincere gratitude to Shri A S Kiran Kumar, Director and Dr R R Navalgund, former Director, SAC, Ahmedabad for providing overall guidance and support. They are grateful to Dr J S Parihar, Deputy Director, EPSA, and Dr Ajai, Group Director, MPSG, SAC, Ahmedabad for providing their valuable guidance and constant encouragement. The work was done as part of project on 'Coastal Processes and Coastal Dynamics', under Meteorology and Oceanography Program (MOP)-2. They also thank Dr P K Pal, Program Director, MOP-2, SAC, Ahmedabad for his support and guidance.

\section{References}

Abbott M B 1979 Computational hydraulics - Elements of the theory of free surface flows (London: Pitman).

Acker J, Quillon S, Gould R and Arnone R 2005 Measuring marine suspended sediment concentration from space: History and potential, International Conference on Remote Sensing for Marine and Coastal Environments, Halifax, Canada, May 17-19, 10p.

Babu K S, Dwarakish G S and Jayakumar S 2003 Modeling of sediment transport along Mangalore coast using MIKE-21; In: Proceedings of International Conference on Coastal and Ocean Technology, 10-12 December 2003, Chennai, India, pp. 301-312.

Babu M T, Vethamony P and Desa E 2005 Modeling tidedriven currents and residual eddies in the Gulf of Kachchh and their seasonal variability, a marine environmental planning perspective; Ecol. Model. 184 299-312.

Cancino L and Neves R 1999 Hydrodynamic and sediment suspension modelling in estuarine systems. Part I: Description of the numerical models; J. Mar. Syst. 22 105-116.

Chauhan O S, Jayakumar S, Menezes A A A, Rajawat A S and Nayak S R 2006 Anomalous inland influx of the River Indus, Gulf of Kachchh, India; Mar. Geol. 229 91-100.

Chauhan O S, Menezes A A A, Jayakumar S, Malik M A, Pradhan Y, Rajawat A S, Nayak S R, Badekar G, Almeida C, Talaulikar M, Ramanamurthy M V and Subramanian B R 2007 Influence of the macro tidal environment on the source to sink pathways of suspended flux in the Gulf of Kachchh, India: Evidence from the Ocean Colour Monitor (IRS-P4); Int. J. Remote Sens. 28 3323-3339.

Doerffer R 1992 Imaging spectroscopy for detection of chlorophyll and suspended matter (eds) Toselli F and Bodechtel J (London: Kluwer Academic Publishers), pp. 215-257.

Douillet P, Quillon S and Cordier E 2001 A numerical model for fine suspended sediment transport in the southwest lagoon of New Caledonia; Coral Reefs 20 361-372.

Erico J D, Miller R L and Brent A M 2007 Suspended particulate matter in coastal waters from ocean color: Application to the northern Gulf of Mexico; J. Geophys. Res. 34 L23611 1-6.

Gordon H R 1997 Atmospheric correction of ocean color imagery in the earth observing system era; J. Geophys. Res. 102 17,081-17,106.
Hashimi N H, Nair R R and Kidwai R M 1978 Sediments of the Gulf of Kutch - a high energy tide dominated environment; Indian J. Mar. Sci. 7 1-7.

Kankara R S, Subramanian B R and Sampath V 2007 Validation of a deterministic hydrodynamic model in the ICZM Framework for Gulf of Kachchh, India; J. Coast. Res. 23(5) 1324-1331.

Kunte P D, Wagle B G and Sugimori Y 2003 Sediment transport and depth variation study of the Gulf of Kachchh using remote sensing; Int. J. Remote Sens. 24 2253-2263.

Kunte P D, Zhao C, Osawa T and Sugimori Y 2005 Sediment distribution study in the Gulf of Kachchh, India, from 3D hydrodynamic model simulation and satellite data; J. Mar. Syst. 55 139-153.

Lee C, Schwab D J, Beletsky D, Stroud J and Lesht B 2007 Numerical modeling of mixed sediment resuspension, transport and deposition during the March 1998 episodic events in southern Lake Michigan; J. Geophys. Res. 112 C02018 1-17.

Liang B, Huajun L and Lee D 2007 Numerical study of threedimensional suspended sediment transport in waves and currents; Ocean Eng. 34 1569-1583.

Miller R L and McKee B A 2004 Using MODIS Terra 250 m imagery to map concentrations of total suspended matter in coastal waters; Rem. Sens. Environ. 93 259-266.

Nair R R, Hashimi N H and Rao P C 1982 On the possibilities of high velocity tidal stream as dynamic barrier to the longhore transport: Evidence from the continental shelf off the Gulf of Kutch - lndia; Mar. Geol. 47 77-86.

Peckham S D 2008 A new method for estimating suspended sediment concentrations and deposition rates from satellite imagery based on the physics of plumes; Comput. Geosci. 34 1198-1222.

Pradhan Y, Rajawat A S and Nayak S R 2004 Application of IRS-P4 OCM data to study the impact of tidal propagation on sediment dynamics in the Gulf of Kachchh; Indian J. Mar. Sci. 34 157-163.

Pradhan Y, Thomaskutty A V, Rajawat A S and Nayak S 2005 Improved regional algorithm to retrieve suspended particulate matter using IRS-P4 ocean colour monitor data; J. Opt. A: Pure Appl. Opt. 7 343-349.

Quillon S and Caussade B 1991 Numerical simulation and remote sensing: Two techniques applied on the Gambia estuary (eds) Sari B D, Brebbia C A and Ouazar D, Computational Mechanics Publications, Springer-Verlag, 3 209-220.

Quillon S, Durand N, Forget P, Fiandrino A and Fraunie P 1998 Remote sensing as a tool for suspended sediment transport modelling in coastal areas; Third International Conference on Multiphase Flow, Lyon France, June 8-12, $8 \mathrm{p}$.

Quillon S, Douiller P and Andrefouet 2004 Coupling satellite data with in situ measurements and numerical modeling to study fine suspended-sediment transport: A study for the lagoon of New Caledonia; Coral Reefs 23 109-122.

Ramaswamy V, Nath B N, Vethamony $\mathrm{P}$ and Illangovan D 2007 Source and dispersal of suspended sediment in the macro-tidal Gulf of Kachchh; Mar. Poll. Bull. 54 708-719.

Shetye S R 1999 Tides in the Gulf of Kachchh, India; Cont. Shelf. Res. 19 1771-1782.

Soulsby R 1997 Dynamics of Marine Sands; 1st edn (London: Thomas Telford Publications).

Tassan S 1994 Local algorithm using SeaWiFS data for retrieval of phytoplankton pigment, suspended sediments and yellow substance in coastal waters; Appl. Opt. 12 2369-2378. 
Ulses C, Estournel C, Durrieu de Madron X and Palanques A 2008 Suspended sediment transport in the Gulf of Lions (NW Mediterranean): Impact of extreme storms and floods; Cont. Shelf. Res. 28 2048-2070.

Unnikrishnan A S and Luick J L 2003 A finite element simulation of tidal circulation in the Gulf of Kutch, India; Estuar. Coast. Shelf. Sci. 56 131-138.
Vethamony P, Reddy G S, Babu M T, Desa E and Sudheesh K 2005 Tidal eddies in a semi-enclosed basin: A model study; Mar. Environ. Res. 59 519-532.

Winter C 2007 On the evaluation of sediment transport models in tidal environments; Sedim. Geol. 202 562-571.

Zhang J and Hua L 2007 A vertical numerical simulation of suspended sediment transport; J. Hydrodyn. 19 217-224.

MS received 7 November 2011; revised 14 February 2012; accepted 16 May 2012 